급성 고립성 현훈으로 내원한 급성 뇌경색 환자에서 위음성을 보인 초기 확산 강조영상

김진옥 이수주

을지대학교 의과대학 을지대학교병원 신경과

\title{
Early False-Negative Diffusion-Weighted Image in Acute Ischemic Stroke Presenting Sudden Isolated Vertigo
}

Jin Ok Kim, Soo Joo Lee

Department of Neurology, Eulji University Hospital, Eulji University School of Medicine, Daejeon, Korea

Diffusion-weighted image (DWI) is commonly used to diagnose acute ischemic stroke in order to differentiate between stroke and stroke mimics. We present two cases of negative DWI for detecting acute ischemic stroke in the emergency department. The follow-up DWI showed small infarction in the nodulus of cerebellum and the medial medulla, respectively. Vertebrobasilar strokes should not be ruled out based on early negative DWI, especially if symptoms persist and central vertigo is suspected.

J Neurosonol Neuroimag 201\$;10(2):169-171

Key Words: Diffusion MRI; Vertigo; Vertebrobasilar insufficiency
Received: October 30, 2018 Revised: December 2, 2018 Accepted: December 4, 2018

Address for correspondence: Soo Joo Lee

Department of Neurology, Eulji University Hospital, Eulji University School of Medicine, 95 Dunsanseo-ro, Seo-gu, Daejeon 35233, Korea Tel: $+82-42-611-3430$ Fax: $+82-42-611-3858$ E-mail: sjoolee@eulji.ac.kr
급성 현훈은 응급실 또는 외래를 방문하는 환자들에게 있어 서 매우 흔한 증상 중 하나이다. 현훈 환자를 진료하는 많은 임상의사의 입장에서 가장 흔한 두려움 중 하나는 뇌경색, 일 과성 뇌허혈 발작 등의 중추성 현훈에 대한 걱정일 것이다. 이 러한 급성 현훈 환자들은 응급실 또는 외래에서 병력 청취와 신체 검진만으로 정확하게 진단하기는 쉽지 않다. 그리고 임 상에서는 확산강조영상(diffusion-weighted image, DWI)을 급성 허혈성 뇌졸중의 가장 정확한 진단법으로 사용하고 있고 이를 급성 현훈 환자에게 뇌졸중을 진단하기 위한 방법으로 이 용하고 있다. 그러나 급성 뇌졸중과 관련된 병변이 종종 확산 강조영상에서도 보이지 않는 경우가 있는데, 이는 급성 허혈성 뇌졸중을 감지하는 민감도가 생각만큼 높지 않을 수 있음을 시 사한다. 저자는 갑자기 발생한 어지럼증으로 응급실 내원하여 확산강조영상을 시행하였지만 제한확산(restricted diffusion) 이 관찰되지 않아 진단이 지연된 증례들을 소개하고 이와 관련 된 간단한 문헌고찰을 하고자 한다.
증 례

1. 증례 1

57 세 남자가 내원 2 일 전에 발생한 어지럼증으로 응급실에 내원하였다. 고혈압으로 약물복용 중이었고 내원 당시 혈압은 $140 / 90 \mathrm{mmHg}$, 맥박은 82회였고 심전도와 기본혈액검사는 정상이었다. 신경학적 진찰에서 좌측으로 향하는 회선성 수평 안진이 관찰되었고, 주시안진(gaze-evoked nystagmus)은 관찰되지 않았으며 두부충동검사(head impulse test)는 우측 에서 양성으로 확인되었다. 다른 신경학적 이상 소견은 관찰되 지 않았으나 앉거나 서있지 못할 정도로 심한 어지럼증을 호소 하였다. 응급실에서 뇌졸중을 배제하기 위하여 확산강조영상 을 시행하였고, 고신호강도를 보이는 이상 소견은 없었다(Fig. $1 \mathrm{~A})$. 전정신경염으로 진단 하에 입원치료를 하였고, 5 일 후에 도 어지럼증은 그대로 지속되고 여전히 앉거나 서지 못하여 확 산강조영상을 재시행하였다. 다시 시행한 확산강조영상에서 좌측 소뇌의 하충부(inferior vermis)에 고신호강도가 관찰되 

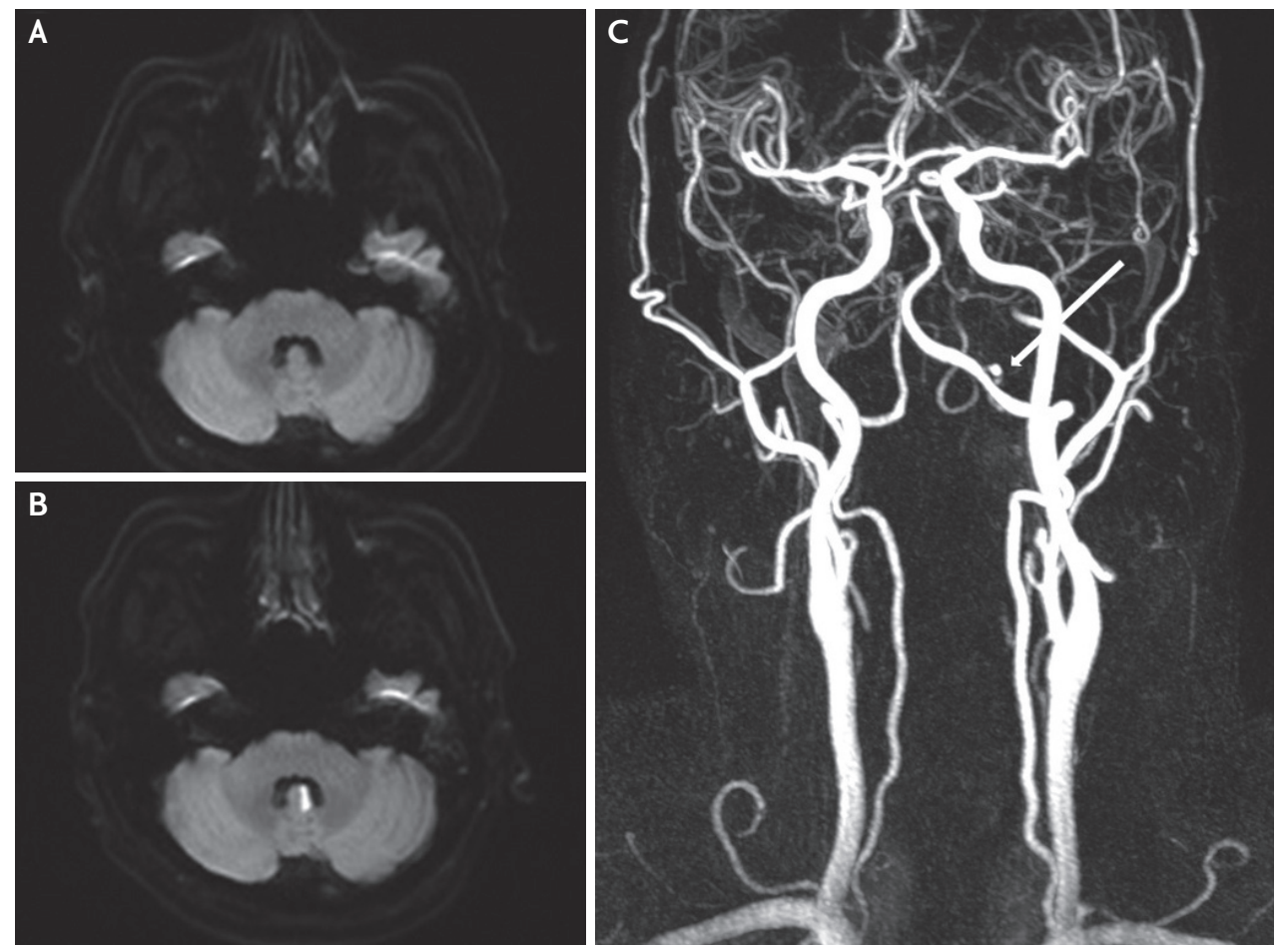

FIG. 1. Diffusion-weighted MRI at admission and follow-up. Follow-up diffusion-weighted MRI and MRA imaging conducted on the first 5 days. (A) Initial diffusion-weighted MRI showed no demonstrable acute or recent infarct. (B) Follow-up diffusion-weighted MRI revealed high signal intensity on left anterior vermis suggesting acute cerebral infarct. (C) MRA imaging showed focal small dissecting aneurysm (about $3.2 \times 2.7 \mathrm{~mm}$ ) at left proximal posterior inferior cerebellar artery branch. MRI; magnetic resonance imaging, MRA; magnetic resonance angiography.
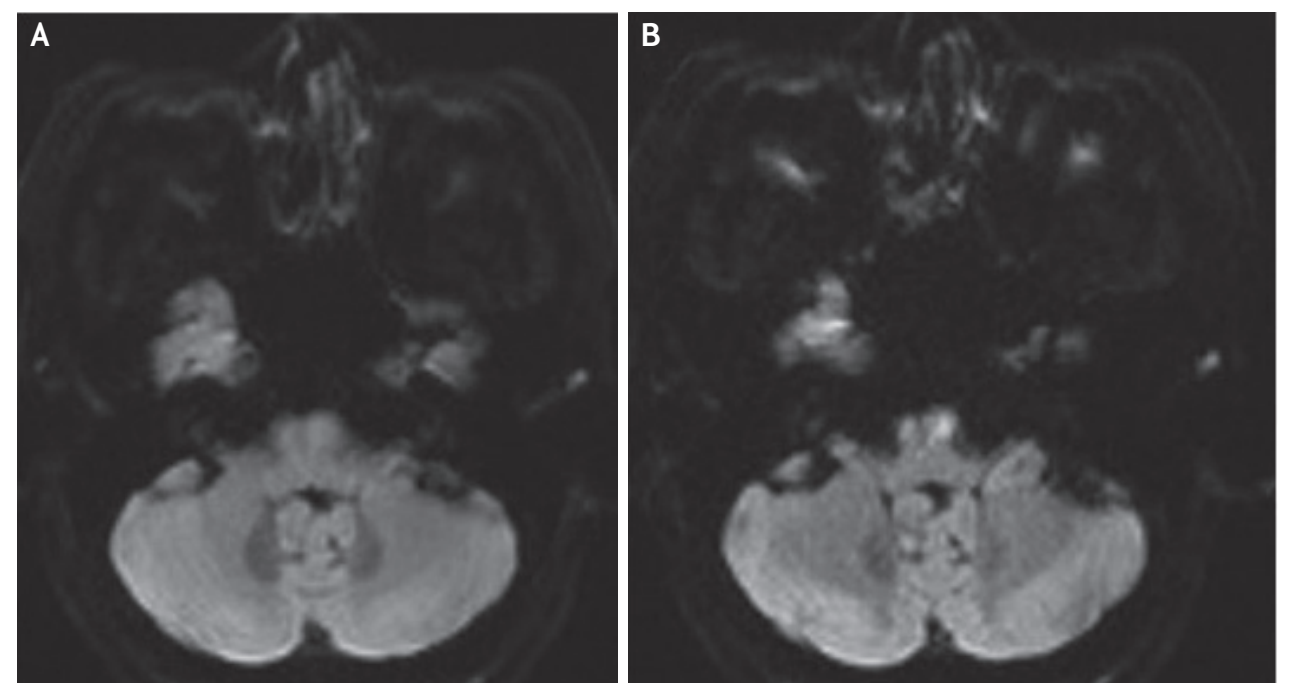

FIG. 2. Diffusion-weighted MRI at admission and follow-up. Follow-up diffusion-weighted MRI and magnetic resonance angiography imaging conducted on the next day. (A) Initial diffusion-weighted MRI showed no demonstrable acute or recent infarct. (B) Follow-up diffusion-weighted MRI revealed high signal intensity on left anteromedial medulla suggesting acute cerebral infarct. MRI; magnetic resonance imaging.

었고(Fig. 1B) 자기공명혈관조영영상에서 좌측 후하소뇌동맥 (posterior inferior cerebellar artery)의 기시부에서 동맥 박리 에 의한 뇌동맥류(cerebral aneurysm)이 관찰되었다(Fig. 1C).

\section{2. 증례 2}

56세 여자가 내원 전일 갑자기 발생한 어지럼증과 시야 흐 림 증상으로 응급실에 내원하였다. 과거력은 없었으며, 응급실 
내원 당시 혈압은 $143 / 92 \mathrm{mmHg}$ 였고, 맥박은 72회였으며 심 전도와 기본혈액검사는 정상이었다. 신경학적 진찰에서 시야 장애, 안구운동장애, 주시안진을 포함한 안진은 보이지 않았고 사지의 조화운동불능 (limb ataxia)을 포함한 국소신경학적 이 상 소견은 관찰되지 않아 고립성 현훈(isolated vertigo)으로 진단하였다. 내원 당일 중추성 현훈을 배제하기 위하여 확산강 조영상을 시행하였고 고신호강도를 보이지 않았다(Fig. 2A), 응급실에서 환자가 호소하는 어지럼증이 약간 호전되어 외래 추적 관찰하기로 하고 퇴원하였으나 다음날 아침부터 말이 어 둔한 증상이 동반되어 다시 응급실에 내원하였고 36시간만에 재시행한 확산강조영상에서 좌측 내측 연수의 제한확산이 관 찰되었고(Fig. $2 \mathrm{~B}$ ), 자기공명혈관조영영상에서 특이 소견은 보이지 않았다.

\section{고 찰}

급성 허혈성 뇌졸중 환자의 진단에 뇌 자기공명영상의 사 용이 크게 증가하였다. 급성 허혈성 뇌졸중의 진단을 위한 뇌 자기공명영상의 이론적 배경은 특히 확산강조영상의 경우 민 감도 88-100\%, 특이도 95-100\%로 뇌 전산화단층촬영영상 (computed tomography)보다 횔씬 높은 것으로 보고되었다. ${ }^{1}$ 또한 뇌 자기공명영상은 급성 뇌출혈을 진단하는데 뇌 전산화 단층촬영영상과 차이를 보이지 않았다.

최근 12 개의 연구 3,236 명의 환자에 대한 메타분석에서 확 산강조영상에서 병변이 관찰되지 않는 확산강조영상-음성 (DWI-negative)인 급성 뇌졸중 빈도는 6.8\%였고, 전방순환 허혈(anterior circulation ischemia)에 의한 신경학적 증상 을 가진 환자보다 후방순환 허혈(posterior circulation ischemia)의 증상을 가진 환자가 5 배 더 많다고 보고하였다. ${ }^{2}$ 다른 연구에서 확산강조영상-음성 뇌경색의 경우에 병변의 평균 크 기는 $0.19 \pm 0.16 \mathrm{~cm}^{3}$ 였으며, 후방순환(19\%)에 의한 뇌경색이 전방순환(2\%)에 의한 뇌경색보다 더 자주 발생한 것으로 보고 되었다. ${ }^{3}$ 확산강조영상-음성에 대한 두 가지 가설이 있는데, 저관류(hypoperfusion)이 확산 병변을 일으킬 정도로 심하지 않거나, 병변의 재관류로 인해서 호전되었을 가능성도 제시되 고 있다. 저관류에 의한 증상 확인을 위해서는 관류강조영상 (perfusion weighted image)이 도움이 될 수 있다. ${ }^{4}$

확산강조영상-음성은 증상 발생 후 처음 24 시간에 흔하였 고, 척추기저동맥 영역의 뇌졸중으로 의심되는 경우에는 증상 이 지속되면 초기 확산강조영상에만 근거하여 뇌졸중의 가능 성을 배제해서는 안 된다. ${ }^{3}$ 이런 진단적인 문제점을 고려하여 확산강조영상 시행 시점이 증상 발생 후 너무 이른(2시간 이 내) 경우는 반드시 추적-반복검사를 권하고 있다. ${ }^{5}$ 횡단면 확 산강조영상(axial DWI) 외에도 얇은 단면의 시상면 확산강조 영상(thin-section sagittal DWI)을 이용하면 거의 추가 시간 없이 뇌간 경색의 위음성(false negative)을 줄일 수 있다. ${ }^{6}$ 물 론 중추성 현훈을 구분하는데 안진, 두부충동검사(head impulse test), 균형장애 등을 확인하여 구분하는 임상적 알고리 즘도 제시되어 있고, 이를 근거로 임상양상으로 판단하는 것도 중요하다. ${ }^{7}$ 하지만 본 증례들과 같이 고립성 현훈인 경우 급성 허혈성 뇌졸중을 진단하는데 있어서 초기 확산강조영상이 음 성이라고 하더라도 완전히 뇌졸중의 가능성을 배제하지 말고, 임상경과를 고려하여 적절한 추적 뇌 자기공명영상을 시행해 야 한다.

\section{REFERENCES}

1. Schellinger PD, Bryan RN, Caplan LR, Detre JA, Edelman RR, Jaigobin C, et al. Evidence-based guideline: the role of diffusion and perfusion MRI for the diagnosis of acute ischemic stroke: report of the Therapeutics and Technology Assessment Subcommittee of the American Academy of Neurology. Neurology. 2010;75:177-185.

2. Edlow BL, Hurwitz S, Edlow JA. Diagnosis of DWI-negative acute ischemic stroke: a meta-analysis. Neurology. 2017;89:256-262.

3. Oppenheim C, Stanescu R, Dormont D, Crozier S, Marro B, Samson Y, et al. False-negative diffusion-weighted MR findings in acute ischemic stroke. AJNR Am J Neuroradiol. 2000;21:1434-1440.

4. Cho TH, Hermier M, Alawneh JA, Ritzenthaler T, Desestret V, Østergaard L, et al. Total mismatch negative diffusion-weighted imaging but extensive perfusion defect in acute stroke. Stroke. 2009;40:3400-3402.

5. Shono K, Satomi J, Tada Y, Kanematsu Y, Yamamoto N, Izu$\mathrm{mi} \mathrm{Y}$, et al. Optimal timing of diffusion-weighted imaging to avoid false-negative findings in patients with transient ischemic attack. Stroke. 2017;48:1990-1992.

6. Schönfeld MH, Ritzel RM, Kemmling A, Ernst M, Fiehler J, Gellißen S. Improved detectability of acute and subacute brainstem infarctions by combining standard axial and thin-sliced sagittal DWI. PLoS One. 2018;13:e0200092.

7. Vanni S, Pecci R, Edlow JA, Nazerian P, Santimone R, Pepe $\mathrm{G}$, et al. Differential diagnosis of vertigo in the emergency department: a prospective validation study of the STANDING algorithm. Front Neurol. 2017;8:590. 